\title{
Performance Evaluation of Rubber Seed Oil Based Cutting Fluid in Turning Mild Steel
}

\author{
A. O. Osayi ${ }^{1}$ *, S. A. Lawal ${ }^{2}$, M. B. Ndaliman ${ }^{3}$, J. B. Agboola ${ }^{4}$ \\ 1,2,3 Department of Mechanical Engineering, Federal University of Technology, Minna, Niger State, NIGERIA. \\ ${ }^{4}$ Department of Metallurgical and Materials Engineering, University of Lagos, NIGERIA.
}

\begin{abstract}
Due to the negative effects associated with the wide use of mineral oil, the desire for eco - friendly cutting fluids as alternative to mineral oil has become a global issue. In this study, rubber seed oil was used to formulate oil-in-water emulsion cutting fluid. Full factorial design was used for the formulation of the oil-in-water emulsion cutting fluid. The optimal process parameters obtained were used for the formulation of the novel cutting fluid and the cutting fluid was characterised. The characteristics of the formulated cutting fluid shows viscosity of $4.25 \mathrm{~mm}^{2} / \mathrm{s}$, pH value of 8.3 , high stability and corrosion resistant. Box-Behnken design was used for the turning operation and the performance of the rubber seed oil cutting fluid was compared with mineral oil. The input parameters were cutting speed, feed rate and depth of cut, while the responses were surface roughness and cutting temperature. Coated carbide insert was used as cutting tool. The ANOVA results show that the feed rate had the most significant effect on the surface roughness and cutting temperature followed by the cutting speed and depth of cut during the turning process. It was observed that the rubber seed oil based cutting fluid reduced surface roughness and cutting temperature by $9.79 \%$ and $1.66 \%$ respectively and therefore, it can be concluded that the rubber seed oil based cutting fluid performed better than the mineral oil in turning of mild steel.
\end{abstract}

Keywords: Rubber oil, Turning, Surface roughness, Temperature

\subsection{INTRODUCTION}

Cutting fluids which are also known as metal working fluids play a vital role in metal removal processes. Conventionally, cutting fluids are used to reduce friction and heat in the cutting zone and thus improve the surface finish of the workpiece and prolong tool life. Basically, cutting fluids perform the functions of lubricating, cooling and flushing out of chips formed during machining operation. During cutting operation, friction and heat are generated between the cutting tool and workpiece and as well as between the cutting tool and chips which lead to increase in temperature at the cutting zone. [1] noted that almost all of the work done in cutting processes is converted to heat that caused high temperature in cutting tool and workpiece surface. [2] observed that the large area of intimate contact between the cutting tool and workpiece results in substantial friction between them, causing the temperature to rise rapidly which facilitates cutting tool failure. High temperature does not only affect the tool wear and tool life it also leads to increase in the surface roughness of the workpiece, the dimensional accuracy and the overall quality of the product. Longer time duration and higher cutting speed results in higher cutting temperature in the

*Corresponding author (Tel: +234 (0) 703601 7767)

Email addresses: a.osayi@futminna.edu.ng (A. O. Osayi) lawalsunday@futminna.edu.ng (S. A. Lawal), mbndaliman@yahoo.com (M. B. Ndaliman), joeagboola@unilag.edu.ng (J. B. Agboola) cutting zone [3]. The effect is more severe when machining the difficult-to-cut materials [4] and [5].

Most of the cutting fluids being used worldwide are mineral oils based types. They are widely used in machining operations because of their excellent performance and cost effectiveness [6]. Despite their extensive use, they pose substantial environmental and health hazards during their life cycle. Basically, the type of oil and additives used in the formulation of cutting fluids determine their effects on the environment. Mineral oil based cutting fluids are poor degradable and they contain several chemical additives to enhance their performance and unfortunately, some of these additives are harmful to the operator and the environment [7].

In view of the foregoing, there is global interest for eco - friendly cutting fluids that will not only meet the characteristics of cutting fluids, but to have better performance and cost effectiveness than mineral oil. From literature a lot of work has been done on edible vegetable oils based cutting fluids and proved to be viable potential alternatives to conventional oil because they are readily biodegradable, low toxicity, eco - friendly and renewable sources. Besides, vegetable oils possess potential properties such as higher viscosity index, higher lubricity, higher load carrying capacity, higher shear stability and lower volatility [8]. However, the sustainability of edible vegetable oils for industrial purposes is now a concern in the cutting fluid industry because they compete with food stuffs especially in developing countries that depend on 
importation to meet their domestic need of the growing population [9] and [10]. In other words, there is a huge of production. Nigeria is heavily dependent on importation of edible oils for domestic consumption and therefore, the sustainability of edible oils for industrial purposes is not feasible in the present-day challenges [11]. With this development, it becomes imperative for researchers to pay more attention to non - edible vegetable oils such as rubber seed oil, jatropha, neem and castor oils as raw materials for industrial purposes like cutting fluids that are not competing with food because they are not edible by human beings. Non-edible vegetable oils derived from plant sources, seem to be more promising for industrial raw materials because they are viable potentials that have not been completely exploited but are being wasted [12]. Rubber seed oil (RSO) has useful properties like soya bean and linseed [13]. The seed oils have several industrial applications such as paint, alkyl resin, soap making, surface coating, biodiesel and bio-lubricant [14], [15] and 16]. Drilling mud and automobile lubricant have been developed from RSO by [17] and [18] respectively. In this study, the main focus was to utilize rubber seed oil to formulate oil -in-water emulsion cutting fluid that is eco-friendly and compare the performance with the mineral oil in turning mild steel. Oil-in-water emulsion (water soluble) cutting fluid is one of the methods being used in machining industry in the world generally and in developing countries particularly because of its inherent combination of excellent cooling and lubricating properties, availability and cost effectiveness [19].

\subsection{MATERIALS AND METHODS \\ $2.1 \quad$ Materials \\ 2.1.1 Cutting Fluid Materials}

The materials for formulation of the cutting fluid in this study include rubber seed oil, distilled water and additives (emulsifier, antioxidant, anti-corrosive agent (banana sap) and biocide) and mineral oil.

\subsubsection{Turning Process Materials and Equipment}

The material for the turning operations is mild steel rod of $600 \mathrm{~mm}$ length and $32 \mathrm{~mm}$ diameter. The equipment used include: Sumore lathe (Model- SP 21100 -11 Shanghai China), cutting tool holder (PCLNR 2020K12, Wodex), tungsten coated carbide tool inserts (SNMG120408), infrared thermometer (Model-ST600, Range: $-32^{\circ} \mathrm{C}-600^{\circ} \mathrm{C}+2 \%$, Shangai, China) and surface roughness tester (Model- SRT-62105, $+10 \%$, Guang Zhoul Landtek).

\subsection{Methods}

2.2.1 Physicochemical Properties and Fatty Acid Composition of Rubber Seed Oil

In this study, the physicochemical properties determined include kinematics viscosity (ASTM D 445), acid value (ASTM D664), flash point (ASTM D 92), pour gap in demand and supply of edible vegetable oils in the market which could lead to increase in price and high cost point (ASTM D 97). The specific gravity, saponification value and iodine value were determined using the expressions by [20]. The $\mathrm{pH}$ value was determined using $\mathrm{pH}$ digital meter and the fatty acid composition was carried out using the Gas Chromatograph (GC).

\subsubsection{Formulation of Rubber Seed Oil Cutting Fluid}

The method used by an earlier researcher [5] was adopted. That is, full factorial design was used for the formulation of the oil-in-water emulsion cutting fluids. A total of 16 runs were designed with variation of input parameters (additives) as follows: emulsifier $(10,130)$; anticorrosion agent $(10,12)$; antioxidant $(0.5,1.0)$ and biocide $(0.5,1.0)$ percentage per weight respectively. The optimal process parameters obtained $(11.50 \%$ of emulsifier (A), $11.00 \%$ of anticorrosion (B), $0.90 \%$ of antioxidant (C) and $0.95 \%$ of biocide (D) were used for formulation of the cutting fluid.

Oil - water ratio of 1:9 was used and the additives that were used are not banned products in composition such as nitrosamines and chlorine for facilitating treatment and disposal process of cutting fluid [5]. Oil and additives were mixed and poured into the water in the measuring cylinder and mechanical stirrer was used for mixing the mixture within 15 minutes. The same ratio of oil-water that was used for the formulation of the rubber seed oil based cutting fluid was used to mix the mineral oil cutting fluid.

\subsubsection{Characterization of the formulated Cutting Fluid \\ Characterization of the novel formulated rubber} seed oil based cutting fluid such as stability, viscosity; corrosion and $\mathrm{pH}$ were carried out in accordance to ASTM standards. The stability of the rubber seed oil cutting fluid was evaluated based on visual transparency. The cutting fluid was filled into $100 \mathrm{ml}$ measuring cylinder and remained within three days at room temperature to determine the appearance and possible oil and water separation.

The kinematic viscosity of the cutting fluid was carried out by ASTM D 445. Corrosion test of the formulated cutting fluid was done by ASTM D 4627. The corrosion test was done by using electric weighing scale to measure $2 \mathrm{~g}$ of dry - cut and clean cast iron chips and placed in a glass cylinder. About $10 \mathrm{ml}$ of the formulated cutting fluid was taken and added to the cast iron chips and shaken for about $60 \mathrm{~s}$ and allowed to soak for few minutes. The cast iron chips were drained and piled on the filter paper and left for about 2 hours. Thereafter, the chips were removed from the filter paper and the filter paper was examined for staining by the damp chips. The $\mathrm{pH}$ value of the cutting fluid was measured by using $\mathrm{pH}$ digital meter. 


\subsubsection{Design of Experiment for Turning Process}

Box-Behnken design was used for the turning process. It is a design for multivariate optimization class of rotatable or nearly rotatable of three level incomplete factorial designs. A total of 15 runs were designed with variation of input parameters. Minitab Statistical Software (2020) was used to carry out the design matrix. The tuning process parameters, their levels and the design matrix are shown in Table 1 and Table 2.

\subsubsection{Turning Process}

A 3-jaw conventional lathe (with speed range of $75-1050 \mathrm{rpm}$ and $3.8 \mathrm{~kW}$ ) was used to carry out the turning process using coated carbide inserts and new cutting edge was used for each experiment.

\subsubsection{Determination of Surface Roughness}

The surface roughness $(\mathrm{Ra} \mu \mathrm{m})$ of the machined workpiece was measured with the aid of surface roughness tester (SRT-6210S). A new cutting edge of the cutting tool inserts was used for each turning operation of the workpiece and thereafter, three measurements were taken at different points along the workpiece surface and the average value was recorded for the analysis.

\subsubsection{Determination of Cutting Temperature}

The temperature of the cutting zone was measured using ST 600 infrared thermometer. The ray is beamed at the cutting zone (point of interface between the cutting tool and the workpiece for about 2 seconds within which the value of the temperature measured is displayed on the screen. Three measurements were taken at different points along the workpiece during machining operation of each run and the average temperature was used for the analysis.

Table 1: Turning Process Parameters and their Levels

\begin{tabular}{lllll}
\hline Parameter & \multicolumn{2}{c}{ Symbol } & \multicolumn{3}{c}{ Level } \\
\hline & & Minimum & Medium & Maximum \\
\cline { 2 - 5 } Cutting speed $(\mathbf{m} / \mathbf{m i n})$ & $(\mathrm{cs})$ & 200 & 220 & 270 \\
Feed rate $(\mathbf{m m} / \mathbf{r e v})$ & $(\mathrm{fr})$ & 0.092 & 0.104 & 0.115 \\
Depth of cut $(\mathbf{m m})$ & $(\mathrm{doc})$ & 0.7 & 1.0 & 1.5 \\
\hline
\end{tabular}

Table 2: Box-Behnken Design Matrix for Turning Process

\begin{tabular}{lccc}
\hline Experiment No & Cs & Fr & doc \\
\hline $\mathbf{1}$ & 200 & 0.092 & 1.1 \\
$\mathbf{2}$ & 270 & 0.092 & 1.1 \\
$\mathbf{3}$ & 200 & 0.115 & 1.1 \\
$\mathbf{4}$ & 270 & 0.115 & 1.1 \\
$\mathbf{5}$ & 200 & 0.104 & 0.7 \\
$\mathbf{6}$ & 270 & 0.104 & 0.7 \\
$\mathbf{7}$ & 200 & 0.104 & 1.5 \\
$\mathbf{8}$ & 270 & 0.104 & 1.5 \\
$\mathbf{9}$ & 220 & 0.092 & 0.7 \\
$\mathbf{1 0}$ & 220 & 0.115 & 0.7 \\
$\mathbf{1 1}$ & 220 & 0.092 & 1.5 \\
$\mathbf{1 2}$ & 220 & 0.115 & 1.5 \\
$\mathbf{1 3}$ & 220 & 0.104 & 1.1 \\
$\mathbf{1 4}$ & 220 & 0.104 & 1.1 \\
$\mathbf{1 5}$ & 220 & 0.104 & 1.1 \\
\hline
\end{tabular}

\subsection{RESULTS AND DISCUSSION}

\subsection{Characterization of Rubber Seed Oil}

The physicochemical properties and fatty acid composition analysis of the rubber seed oil are shown in Table 3 and Table 4, while the GC-MS of the RSO is shown in Figure 1. The specific gravity of rubber oil (0.920) is in agreement with that of rubber seed (0.91) (21] and the low value indicates good property because the lighter the better for cutting fluid formulation as heavier oil will not easily flow in between the chips and the cutting tool for effective cooling. The viscosity of rubber seed $\left(68.37 \mathrm{~mm}^{2} / \mathrm{s}\right)$ at $40^{\circ} \mathrm{C}$ is comparable to those of neem oi $\left(68.04 \mathrm{~mm}^{2} / \mathrm{s}\right)[22]$ and rubber seed $\left(66 \mathrm{~mm}^{2} / \mathrm{s}\right)$ [21]. This indicates that the lubricating property of the oil is high. The acid value of rubber seed oil $(7.29 \mathrm{mg}$ $\mathrm{KOH} / \mathrm{g}$ ) is comparable to that of melon oil (9.39) [23]. The saponification value of rubber seed $(163.60 \mathrm{mg}$ $\mathrm{KOH} / \mathrm{g})$ is comparable to that of neem $(166 \mathrm{mgKOH} / \mathrm{g})$ [22]. The rubber seed oil has iodine value $(53.29 \mathrm{mg} / \mathrm{g})$ and is comparable to palm oil (54.24) [24]. The $\mathrm{pH}$ value of rubber seed (5.42) is comparable with beniseed (5.28) 
[23]. Though the $\mathrm{pH}$ value shows that the oil is acidic, however, blending with water and other additives will normalise it for safe use. The flash point value of rubber Abundance seed $\left(245^{\circ} \mathrm{C}\right)$ is within that of quassia undulated seed $\left(255^{\circ} \mathrm{C}\right)[25]$. The high flash point of the rubber seed oil shows that it is safe for handling.

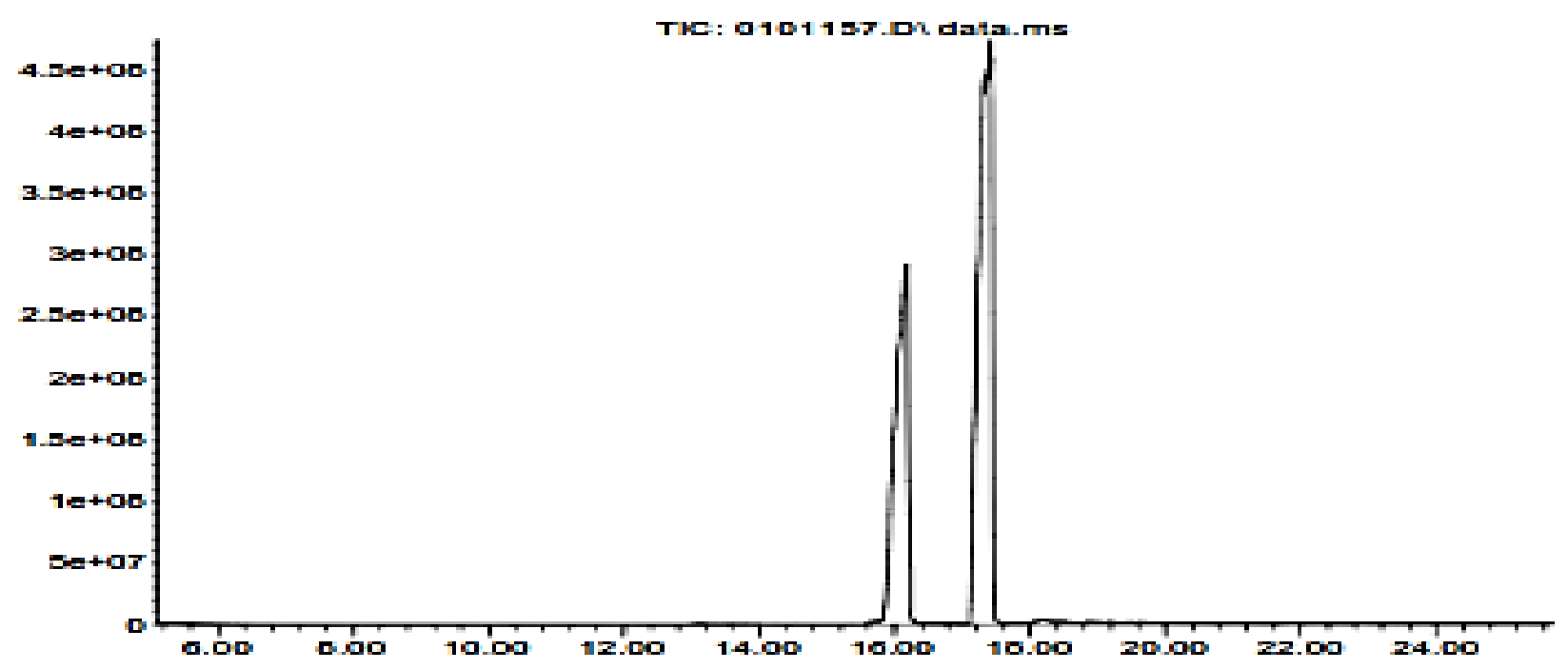

Time

Figure 1: Gas chromatograph of rubber seed oil

Table 3: Physicochemical properties of rubber seed oil

\begin{tabular}{ll}
\hline Property & Rubber Seed Oil \\
\hline Specific Gravity & 0.920 \\
Kinematic Viscosity @ $\mathbf{4 0}^{\mathbf{0}} \mathbf{C}\left(\mathbf{m m}^{2} / \mathbf{s}\right)$ & 68.37 \\
Acid Value $(\mathbf{m g K O H} / \mathbf{g})$ & 7.29 \\
Saponification Value $(\mathbf{m g K O H} / \mathbf{g})$ & 163.37 \\
Iodine Value (mgl/g) & 53.29 \\
pH Value & 5.42 \\
Flash Point ${ }^{\mathbf{0}} \mathbf{C}$ & 245 \\
Pour Point ${ }^{\mathbf{C}} \mathbf{C}$ & -12 \\
\hline
\end{tabular}

The specific gravity of rubber oil $(0.920)$ is in agreement with that of rubber seed (0.91) (21] and the low value indicates good property because the lighter the better for cutting fluid formulation as heavier oil will not easily flow in between the chips and the cutting tool for effective cooling. The viscosity of rubber seed (68.37 $\mathrm{mm}^{2} / \mathrm{s}$ ) at $40^{\circ} \mathrm{C}$ is comparable to those of neem oi $\left(68.04 \mathrm{~mm}^{2} / \mathrm{s}\right)$ [22] and rubber seed $\left(66 \mathrm{~mm}^{2} / \mathrm{s}\right)$ [21]. This indicates that the lubricating property of the oil is high. The acid value of rubber seed oil $(7.29 \mathrm{mg} \mathrm{KOH} / \mathrm{g})$ is comparable to that of melon oil (9.39) [23]. The saponification value of rubber seed $(163.60 \mathrm{mg} \mathrm{KOH} / \mathrm{g})$ is comparable to that of neem $(166 \mathrm{mgKOH} / \mathrm{g})$ [22]. The rubber seed oil has iodine value $(53.29 \mathrm{mg} / \mathrm{g})$ and is comparable to palm oil (54.24) [24]. The $\mathrm{pH}$ value of rubber seed (5.42) is comparable with beniseed (5.28) [23]. Though the $\mathrm{pH}$ value shows that the oil is acidic, however, blending with water and other additives will normalise it for safe use. The flash point value of rubber seed $\left(245^{\circ} \mathrm{C}\right)$ is within that of quassia undulated seed $\left(255^{\circ} \mathrm{C}\right)$ [25]. The high flash point of the rubber seed oil shows that it is safe for handling.

Table 4: Fatty acid compositions of rubber seed oil

\begin{tabular}{lll}
\hline Name of Acid & Form & Rubber seed oil Value (\%) \\
\hline Hexadecanoic acid & $\mathrm{C} 17 \mathrm{H} 32 \mathrm{O} 2$ & 18.02 \\
Pentadecanoic acid & $\mathrm{C} 19 \mathrm{H} 34 \mathrm{O} 2$ & 5.43 \\
9-octadecenoic acid & $\mathrm{C} 21 \mathrm{H} 40 \mathrm{O} 2$ & 50.47 \\
Trans-13-octadecenoic acid & $\mathrm{C} 19 \mathrm{H} 36 \mathrm{O} 2$ & 14.82 \\
11-octadecenoic acid & $\mathrm{C} 18 \mathrm{H} 34 \mathrm{O} 2$ & 9.18 \\
Others & & 2.08 \\
Total Saturated & & 23.45 \\
Total Unsaturated & & 74.47 \\
\hline
\end{tabular}


The fatty acid composition of the rubber seed oil shows five main fatty acids which are: hexadecanoic acid $(18.02 \%)$, pentadecanoic acid $(5.43 \%)$, 9-octadecanoic acid $(50.47 \%)$, trans -13 -octadecanoic acid $(14.82 \%)$ and 11-octadecanoic acid (9.18\%). Table 4 shows that the rubber seed oil contains approximately $23.45 \%$ saturated acids and $74.47 \%$ unsaturated acids and is high oleic unsaturated vegetable oil which can be used as feedstock for eco-friendly cutting fluid.

\subsection{Characterization of the Formulated Cutting Fluid}

The results of the characterization of the formulated rubber seed oil cutting fluid are shown in Table 5.

From Table 5, it could be observed that the viscosity of the formulated rubber seed oil based cutting fluid is 4.25 $\mathrm{mm}^{2} / \mathrm{s}$ and is in agreement with the viscosity $4.39 \mathrm{~mm}^{2} / \mathrm{s}$ of castor oil emulsion cutting fluid [26]. The rubber seed oil based cutting fluid with $\mathrm{pH}$ value of 8.3 compares favourably with the $\mathrm{pH}$ value 8.2 of melon seed oil cutting fluid [23]. The stability test of the cutting fluids as described in section 2.2.3, showed that there was no phase separation of oil and water which indicates that the cutting fluid is stable.

\subsection{Experimental Results and S/N Ratios}

Surface roughness and cutting temperature were the responses evaluated during the turning processes for the rubber seed oil and mineral oil cutting fluids. The data and their corresponding $\mathrm{S} / \mathrm{N}$ ratios of the surface roughness and temperature of each cutting fluid are shown in Table 6.

Table 5: Characteristics of rubber oil and mineral oil cutting fluids

\begin{tabular}{llll}
\hline S/N & Property & $\begin{array}{l}\text { Value } \\
\text { Rubber Seed oil }\end{array}$ & Mineral oil \\
\hline $\mathbf{1}$ & Viscosity $\left(\mathrm{mm}^{2} / \mathrm{s}\right)$ & 4.25 & 0.75 \\
$\mathbf{2}$ & pH value & 8.3 & 8.04 \\
$\mathbf{3}$ & Stability & stable & stable \\
$\mathbf{4}$ & Corrosion level & corrosion resistant & corrosion resistant \\
$\mathbf{5}$ & Colour & Milky & Milky \\
\hline
\end{tabular}

Table 6: Experimental results and their corresponding $\mathrm{S} / \mathrm{N}$ ratios

\begin{tabular}{|c|c|c|c|c|c|c|c|c|}
\hline \multirow{2}{*}{$\begin{array}{l}\text { Exp. } \\
\text { Run }\end{array}$} & \multirow{2}{*}{$\begin{array}{l}\mathrm{Ra}(\mu \mathrm{m}) \\
\text { Rubber } \\
\text { oil }\end{array}$} & \multirow[b]{2}{*}{ Mineral oil } & \multicolumn{2}{|l|}{$\mathrm{S} / \mathrm{N}$} & \multicolumn{2}{|c|}{ Temp. $\left({ }^{\circ} \mathrm{C}\right)$} & \multicolumn{2}{|l|}{$\mathrm{S} / \mathrm{N}$} \\
\hline & & & $\begin{array}{l}\text { Rubber } \\
\text { oil }\end{array}$ & Mineral & $\begin{array}{l}\text { Rubber } \\
\text { oil }\end{array}$ & $\begin{array}{c}\text { Mineral } \\
\text { oil }\end{array}$ & $\begin{array}{l}\text { Rubber } \\
\text { Oil }\end{array}$ & $\begin{array}{l}\text { Mineral } \\
\text { oil }\end{array}$ \\
\hline 1 & 0.72 & 0.86 & 2.8534 & 1.3100 & 35.2 & 35.4 & -30.9309 & -30.9800 \\
\hline 2 & 0.55 & 0.62 & 5.1927 & 4.1522 & 36.7 & 38.2 & -31.2933 & -31.6413 \\
\hline 3 & 0.93 & 1.06 & 0.6303 & 0.5061 & 39.1 & 39.7 & -31.8435 & -31.9758 \\
\hline 4 & 0.84 & 0.94 & 1.5144 & 0.5374 & 42.0 & 42.5 & -32.4650 & -32.5678 \\
\hline 5 & 0.71 & 0.74 & 2.9748 & 2.6154 & 38.9 & 39.4 & -31.7990 & -31.9099 \\
\hline 6 & 0.60 & 0.66 & 4.4370 & 3.6091 & 39.0 & 40.5 & -31.8213 & -32.1491 \\
\hline 7 & 0.74 & 0.77 & 2.6154 & 2.2702 & 38.0 & 39.6 & -31.5957 & -31.9539 \\
\hline 8 & 0.61 & 0.68 & 4.2934 & 3.3498 & 40.0 & 40.1 & -32.0412 & -32.0629 \\
\hline 9 & 0.57 & 0.61 & 4.8825 & 4.2934 & 35.9 & 36.0 & -31.1019 & -31.0777 \\
\hline 10 & 0.80 & 0.90 & 1.9382 & 0.9151 & 39.7 & 40.6 & -31.9758 & -32.1705 \\
\hline 11 & 0.69 & 0.77 & 3.2230 & 2.2702 & 36.2 & 36.8 & -31.1742 & -31.3170 \\
\hline 12 & 0.81 & 0.99 & 1.8303 & 0.0873 & 40.2 & 40.6 & -32.0845 & -32.1705 \\
\hline 13 & 0.68 & 0.70 & 3.3498 & 3.0980 & 39.5 & 39.8 & -31.9319 & -31.9977 \\
\hline 14 & 0.67 & 0.72 & 3.4785 & 2.8534 & 39.2 & 39.9 & -31.8657 & -32.0195 \\
\hline 15 & 0.68 & 0.70 & 3.3498 & 0.2491 & 39.4 & 39.7 & -31.9099 & -31.9758 \\
\hline
\end{tabular}

\subsection{Signal-to Noise Ratio of Responses}

\subsubsection{Surface Roughness}

The main effect plots for surface roughness of rubber oil and mineral oil cutting fluids are shown in Figure 2 and Figure 3.

Figure 2 shows the main effects plot of $\mathrm{S} / \mathrm{N}$ ratio for surface roughness using rubber oil based cutting fluid.
It can be observed that the optimal turning parameters for minimum surface roughness are $270 \mathrm{~m} / \mathrm{min}$ of cutting speed (level 3), $0.092 \mathrm{~mm} / \mathrm{rev}$ of feed rate (level 1) and $0.7 \mathrm{~mm}$ of depth of cut (level 1). From the result, it can be deduced that high speed, low feed rate and low depth of cut reduce the surface roughness in machining and this is in agreement with the work by [2]. 


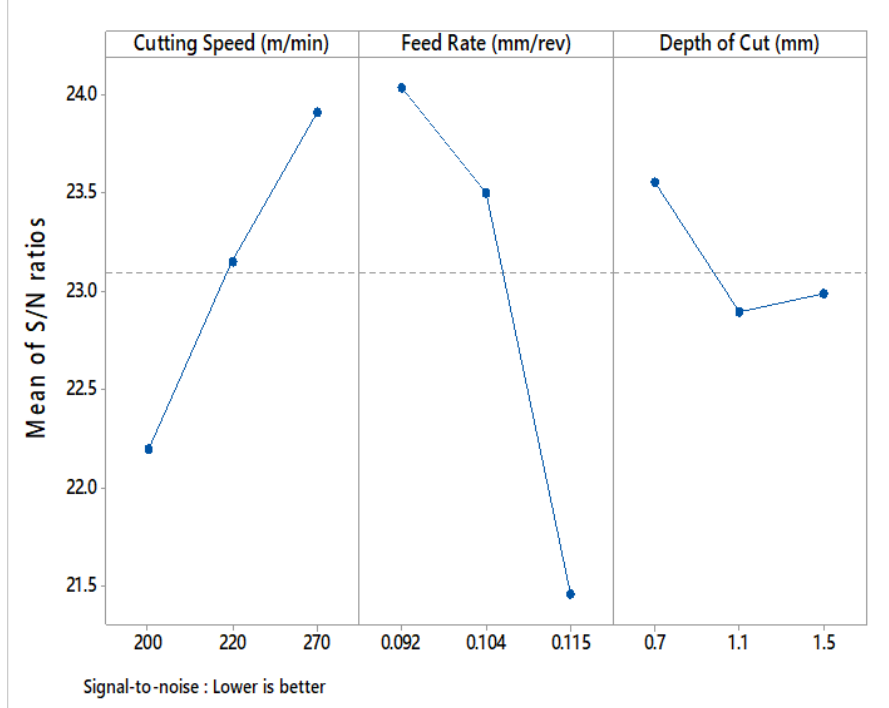

Figure 2: Main effect plot for rubber seed oil

The predicted surface roughness, $\mathrm{Ra}(\mu \mathrm{m})$ value for rubber seed oil based cutting fluid is expressed by the regression model:

$\mathrm{Ra}=0.071417-0.00014 \mathrm{cs}-0.00836 \mathrm{fr}+0.03020 \mathrm{doc}$

$\mathrm{R} 2=94.42 \%, \mathrm{R} 2=90.24 \%$

The model equation for surface roughness, $\mathrm{Ra}(\mu \mathrm{m})$ for conventional cutting fluid is:

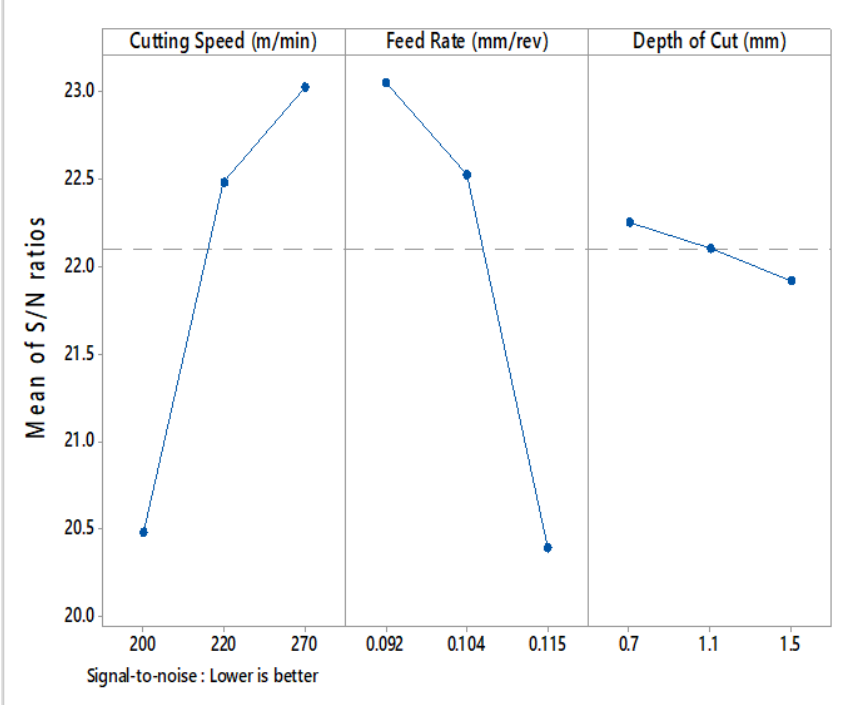

Figure 3: Main effect plot for mineral oil

$\mathrm{Ra}=0.08000-0.00014 \mathrm{cs}-0.00840 \mathrm{fr}+0.02530 \mathrm{doc}$

$\mathrm{R} 2=94.50 \%, \mathrm{R} 2=90.37 \%$.

Figure 3 shows the main effect plots of $\mathrm{S} / \mathrm{N}$ ratio for surface roughness using mineral oil. It can be observed that the optimal turning parameters for minimum surface roughness are $270 \mathrm{~m} / \mathrm{min}$ of cutting speed (level 3), 0.092 $\mathrm{mm} / \mathrm{rev}$ of feed rate (level 1) and $0.7 \mathrm{~mm}$ of depth of cut (level 1) respectively. The effect of the different cutting fluids on surface roughness at various cutting speeds is as shown in Figure 4.

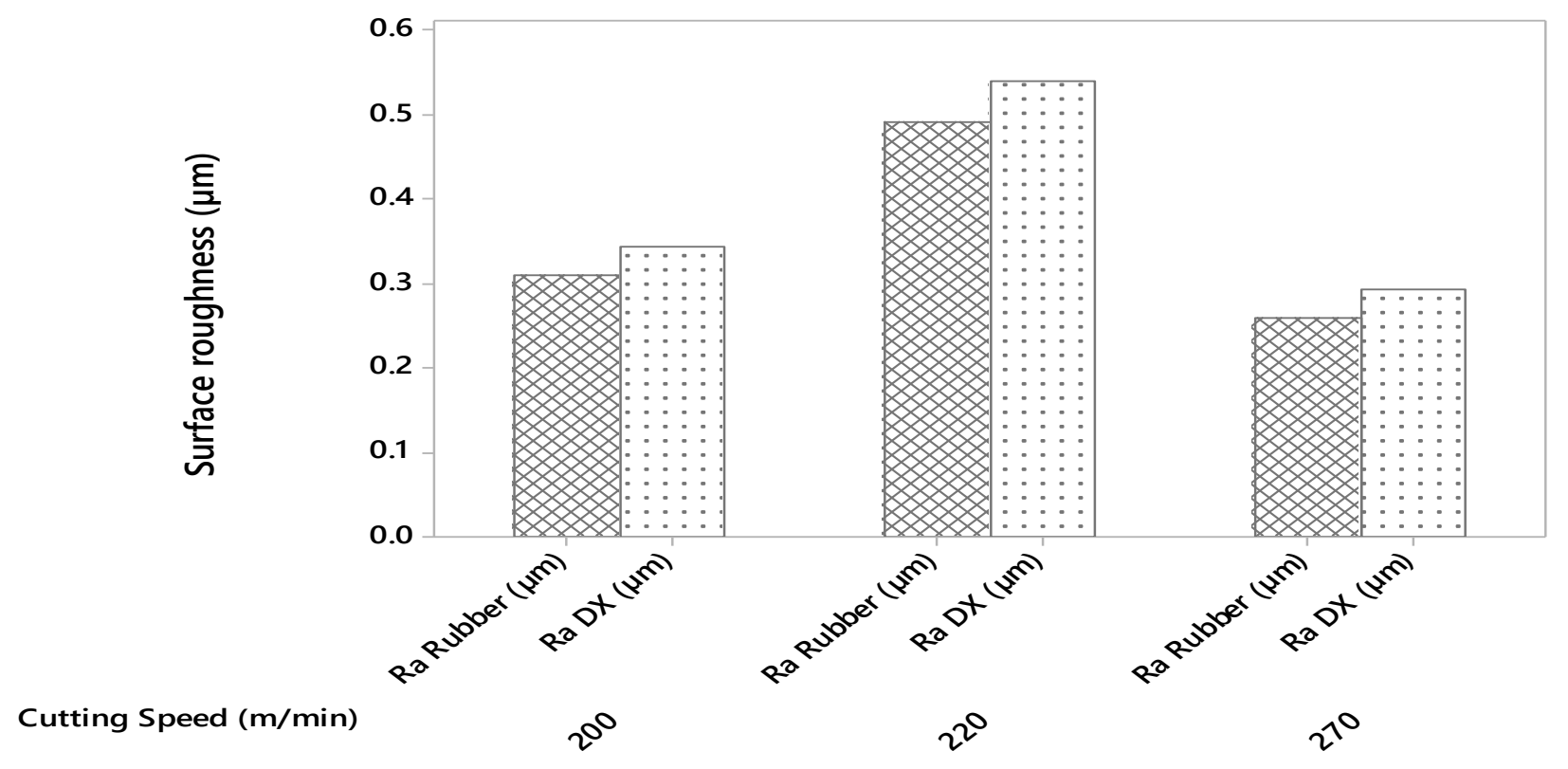

Figure 4: Effect of the different cutting fluids on surface roughness at various speeds

Figure 4 shows the effects of the different cutting fluids on surface roughness at various cutting speeds in the following: At lower cutting speed of $200 \mathrm{~m} / \mathrm{min}$, rubber seed cutting fluid reduced the surface roughness by $9.62 \%$ as compared to the mineral oil and at $220 \mathrm{~m} / \mathrm{min}$ cutting speed, the rubber cutting fluid reduced the surface 
roughness by $9.09 \%$. At $270 \mathrm{~m} / \mathrm{min}$ speed, the percentage reduction for rubber oil was $11.26 \%$ respectively. It can be observed that the rubber seed oil based cutting fluid with higher viscosity $4.25 \mathrm{~mm}^{2} / \mathrm{s}$ showed more influence on the surface roughness than the mineral oil cutting fluid with viscosity $0.75 \mathrm{~mm}^{2} / \mathrm{s}$ at the various cutting speed conditions. Therefore, it can be concluded that the rubber seed oil based cutting fluid performed better as compared to the mineral oil with respect to the surface roughness. The different behaviour of the rubber seed oil based cutting fluid can be attributed to higher viscosity, lubricity and exceptionality of their structure and fatty acid compositions. This is in agreement with the work by [5].

\subsubsection{Cutting Temperature}

The main effect plots for cutting temperature of rubber oil and mineral oil cutting fluids are shown in Figure 5 and Figure 6.

From the main effect plots, in Figure 5 and Figure 6 , it can be observed that the optimal input parameters for temperature are: $200 \mathrm{~m} / \mathrm{min}$ (level 1), feed rate of 0.092 $\mathrm{mm} / \mathrm{rev}$ (level 1) and depth of cut of $0.7 \mathrm{~mm}$ (level 1) for both cutting fluids during turning operations. From the results, it can be deduced that the cutting temperature decreases with decreased in cutting speed and feed rate and verse versa.

The model equation for cutting temperature $\left({ }^{\circ} \mathrm{C}\right)$ for rubber seed oil based cutting fluid is:

Cutting temperature $(\mathrm{Tp})=39.6500-0.0221 \mathrm{cs}-2.4740 \mathrm{fr}$ -0.2450 doc

$\mathrm{R}^{2}=94.98 \%, \mathrm{R}^{2}$ adjusted $=91.22 \%$.

The model equation for cutting temperature $\left({ }^{\circ} \mathrm{C}\right)$ for conventional seed oil is:

Cutting temperature $(\mathrm{Tp})=39.1170-0.0144 \mathrm{cs}-2.5000 \mathrm{fr}$ -0.1990 doc

$\mathrm{R} 2=95.22 \%, \mathrm{R} 2$ adjusted $=91.64 \%$

The effect of the different cutting fluids on cutting temperature at various speeds is as shown in figure 7

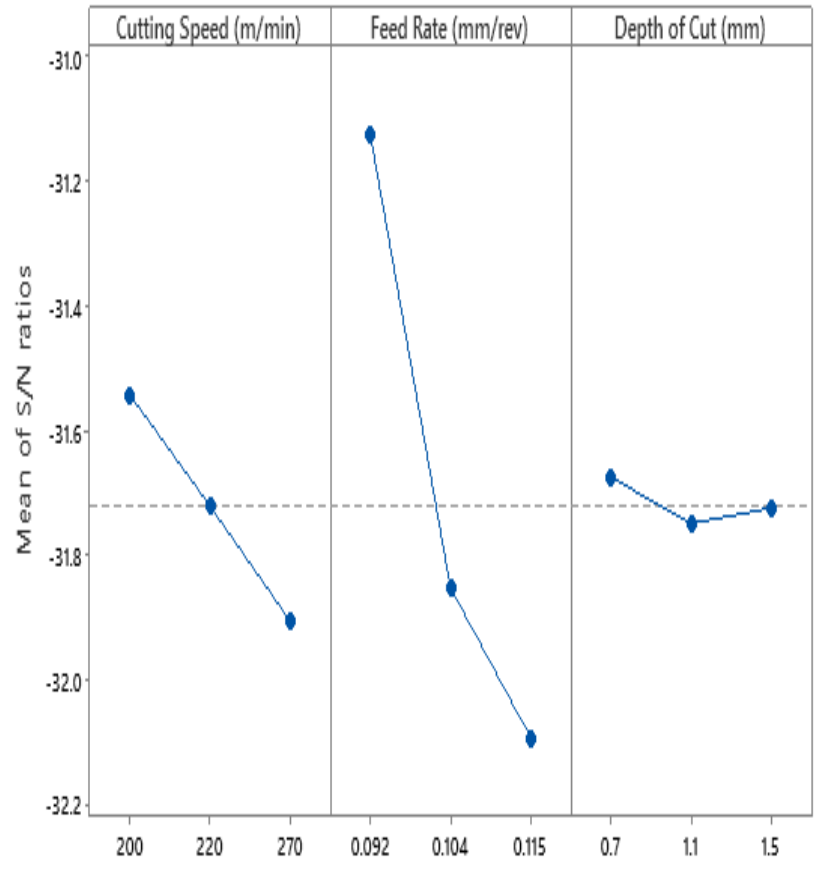

Signal to Noise: Lower is better

Figure 5: Main effect plot for rubber seed oil

Figure 7 shows the effect of the different cutting fluids on cutting temperature at various cutting speeds in the following: At lower cutting speed of $200 \mathrm{~m} / \mathrm{min}$, rubber seed oil cutting fluid reduced the cutting temperature by $1.88 \%$ compared to mineral oil and at 220 $\mathrm{m} / \mathrm{min}$ cutting speed, the rubber oil cutting fluid reduced the cutting temperature by $1.21 \%$. At $270 \mathrm{~m} / \mathrm{min}$ speed,

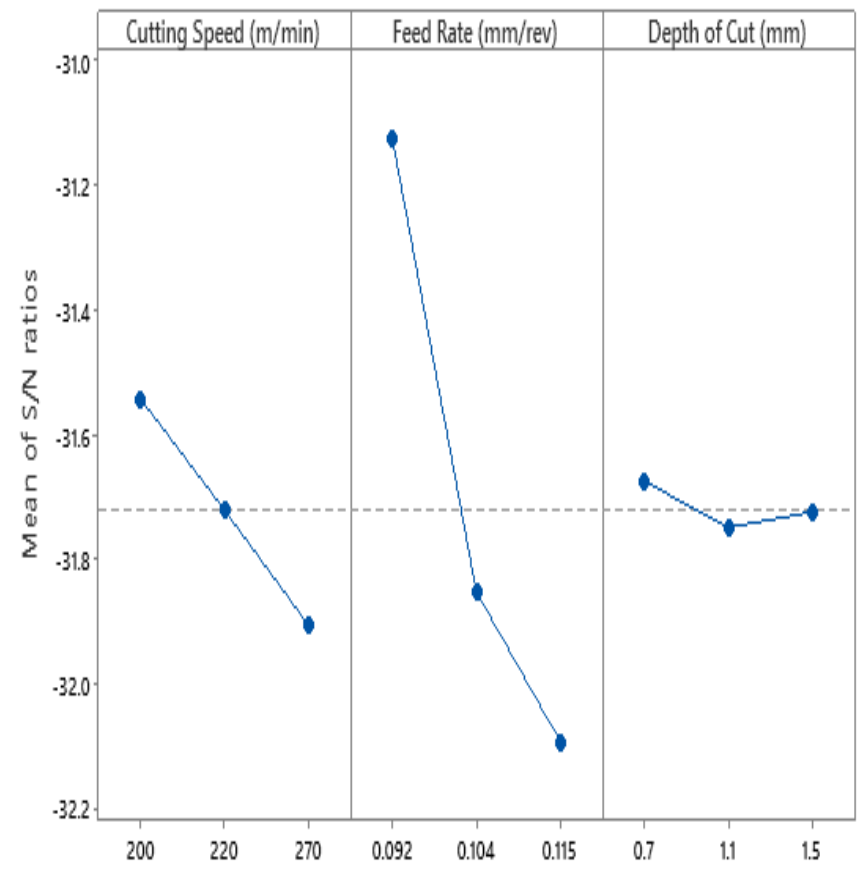

Signal to Noise: Lower is better

Figure 6: Main effect plot for mineral oil

the percentage reduction for rubber oil was $2.23 \%$ respectively.

From the result, it can be observed that the rubber seed oil cutting fluid with viscosity $4.25 \mathrm{~mm}^{2} / \mathrm{s}$ had lower cutting temperature than the mineral oil cutting fluid with viscosity of $0.75 \mathrm{~mm}^{2} / \mathrm{s}$ at various speeds. This may be attributed to higher viscosity and the combination of 
cooling and lubrication properties of rubber seed oil because the viscosity significantly affects the thickness of the lubricating film formed from cutting fluid during machining. This is in agreement with the studies by [28].

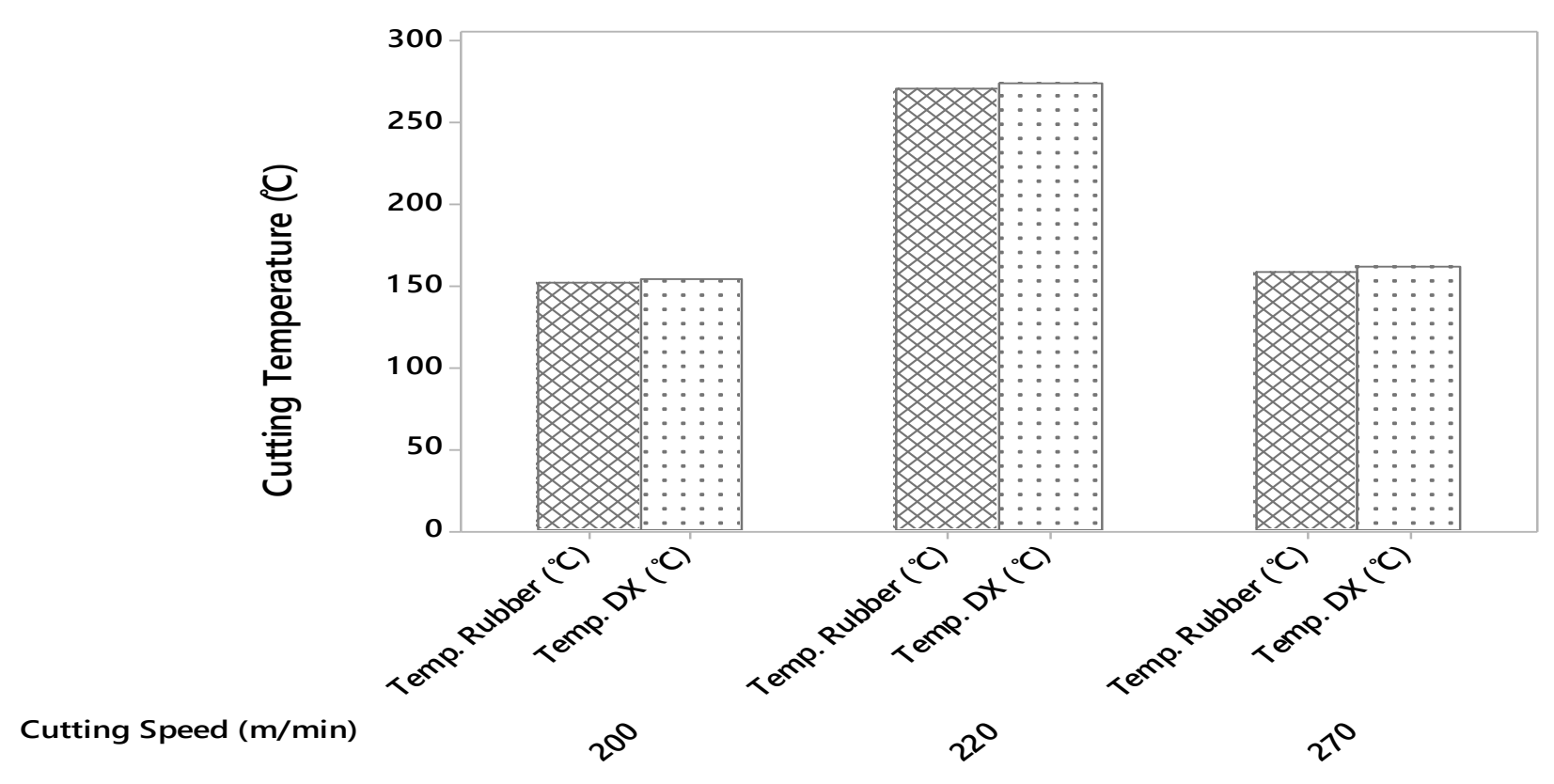

Figure 7: Effect of the different cutting fluids on cutting temperature at various speeds.

\subsection{Analysis of Variance}

Minitab Statistical Software was used to carry out the ANOVA analysis for surface roughness and cutting temperature and the results are shown in Table 3.5 and Table 3.6.

It can be observed that the percentage contribution of each input parameters to the surface roughness are: cutting speed $(20.79 \%)$, feed rate $(69.50 \%)$ and depth of cut $(4.08 \%)$ respectively. The results show that the feed rate has the most significant effect on the surface roughness, followed by the cutting speed and depth of cut respectively. Therefore, it can be concluded that the cutting speed and feed rate have more significant effect on the surface roughness in the turning operation. This is in agreement with the work by [27].

From Table 7, the ANOVA of surface roughness using mineral oil, it can be observed that the percentage contributions of input parameters to the surface roughness are: cutting speed (14.44\%), feed rate $(75.05 \%)$ and depth of cut $(5.01 \%)$ respectively. The results show that the feed rate has the most significant effect on the surface roughness, followed by the cutting speed and depth of cut respectively. This is in agreement with the work by [27].

Table 7: ANOVA for surface roughness for rubber seed oil and mineral oil cutting fluids

\begin{tabular}{|c|c|c|c|c|c|c|c|c|c|c|}
\hline \multirow[t]{2}{*}{ Variable } & \multicolumn{5}{|c|}{ Rubber seed oil } & \multicolumn{5}{|c|}{ Mineral oil } \\
\hline & DOF & SS & MS & $\mathbf{F}$ & $\mathbf{P}(\%)$ & DOF & SS & MS & $\mathbf{F}$ & $\mathbf{P}(\%)$ \\
\hline CS (m/min) & 2 & 0.0321 & 0.0161 & 14.8 & 20.79 & 2 & 0.0383 & 0.0191 & 10.45 & 14.44 \\
\hline FR (mm/rev) & 2 & 0.1073 & 0.0537 & 3 & 69.50 & 2 & 0.1991 & 0.0995 & 54.39 & 75.05 \\
\hline DOC (mm) & 2 & 0.0063 & 0.0032 & 49.5 & 4.08 & 2 & 0.0133 & 0.0066 & 3.62 & 5.01 \\
\hline Error & 8 & 0.0087 & 0.0011 & 4 & 5.63 & 8 & 0.0146 & 0.0018 & & 5.5 \\
\hline Total & 14 & 0.1544 & & 2.92 & 100 & 14 & 0.2653 & & & 100 \\
\hline
\end{tabular}

Table 8: ANOVA for cutting temperature of rubber seed oil and mineral oil cutting fluids

\begin{tabular}{lllllllllll}
\hline Variable & \multicolumn{1}{l}{ Rubber seed oil } & \multicolumn{7}{c}{ Mineral oil } \\
& DOF & SS & \multicolumn{1}{c}{ MS } & F & P(\%) & DOF & SS & MS & F & P(\%) \\
\hline CS (m/min) & 2 & 5.2998 & 2.6499 & 8.77 & 10.97 & 2 & 6.7592 & 3.3796 & 11.27 & 13.49 \\
FR (mm/rev) & 2 & 40.1635 & 20.0818 & 66.48 & 83.13 & 2 & 40.7981 & 20.3990 & 68.00 & 81.41 \\
DOC (mm) & 2 & 0.4813 & 0.2407 & 0.80 & 1.00 & 2 & 0.1581 & 0.0790 & 0.26 & 0.31 \\
Error & 8 & 2.4167 & 0.3021 & & 5.00 & 8 & 2.4000 & 0.3000 & & 4.79 \\
Total & 14 & 48.3146 & & & & 14 & 50.1154 & & & \\
\hline
\end{tabular}


From Table 7, the ANOVA of cutting temperature for rubber seed oil cutting fluid, it can be observed that the percentage contributions of input parameters to the cutting temperature are: cutting speed $(10.97 \%)$, feed rate $(83.13 \%)$ and depth of cut $(1.00 \%)$ respectively. It indicates that feed rate is the most significant parameter that influences the cutting temperature in this study. This is in agreement to the work by [23].

From Table 8, the ANOVA of cutting temperature for mineral oil, it can be observed that the percentage contributions of input parameters to the cutting temperature are: cutting speed $(13.49 \%)$, feed rate $(81.41 \%)$ and depth of cut $(0.31 \%)$ respectively. This is in agreement to the work by [23].
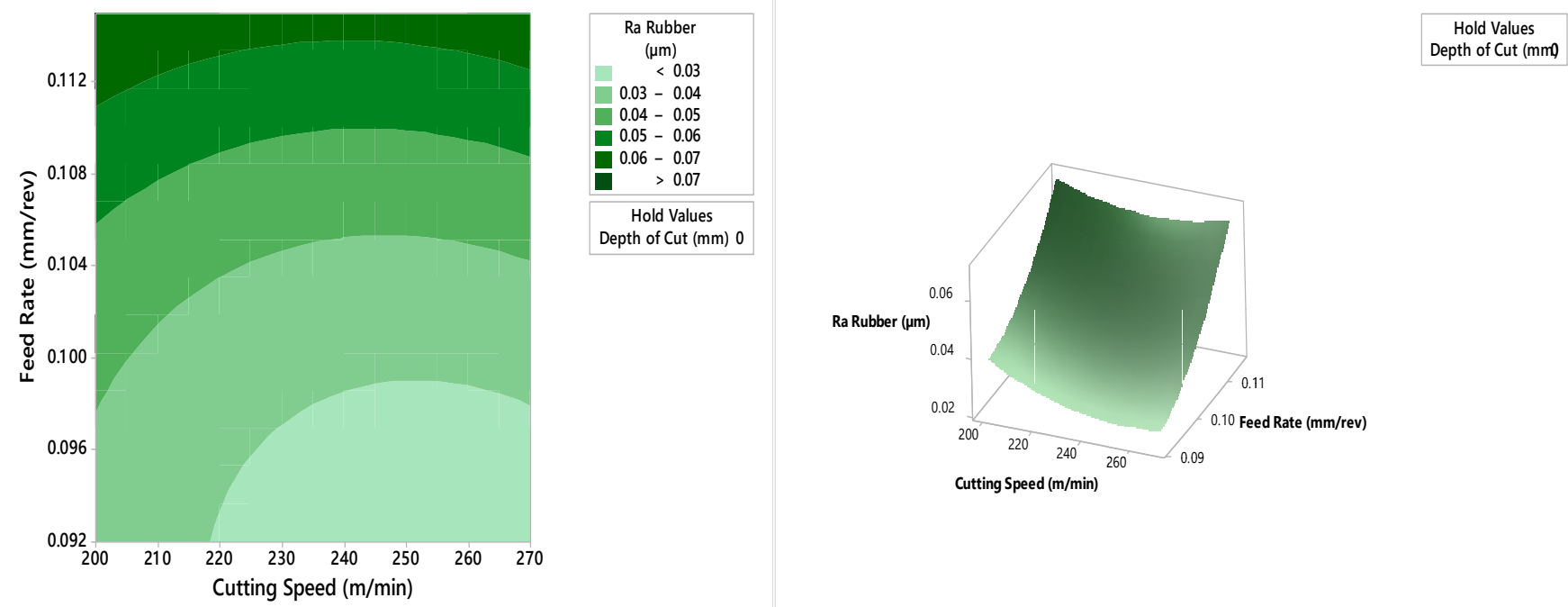

Figure 8: Contour and 3D plots for surface roughness for rubber oil

\subsection{Contour Plots and 3D Surface Plots}

The contour and 3D surface plots for interaction effects of surface roughness and cutting temperature for rubber seed oil and mineral oil cutting fluids are shown in Figures $8-11$. Figures $8-11$ show the contour and 3D surface plots for interaction effect of cutting speed and feed rate on the surface roughness and cutting temperature when depth of cut held constant. It can be deduced that the surface roughness and cutting temperature increased with increase in cutting speed and feed rate when both cutting fluids were used. The 3D surface plots show the effect of cutting speed and feed rate on the surface roughness and cutting temperature with flattened curve shapes design model. It is observed that the surface roughness and cutting temperature increased with increased in cutting speed and feed rate. This agrees with the contour plots.
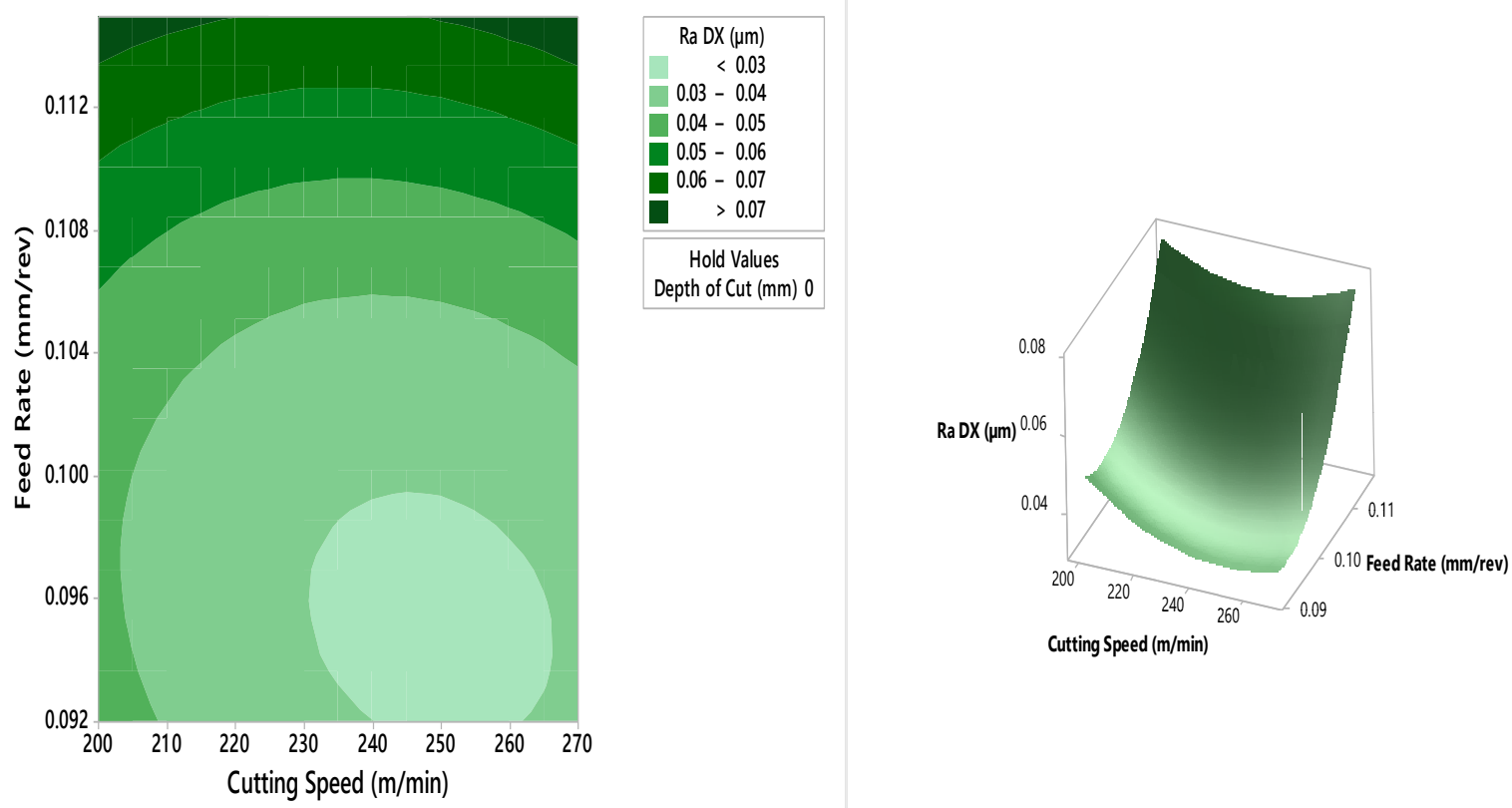

Figure 9: Contour and 3D plots for surface roughness for mineral oil. 

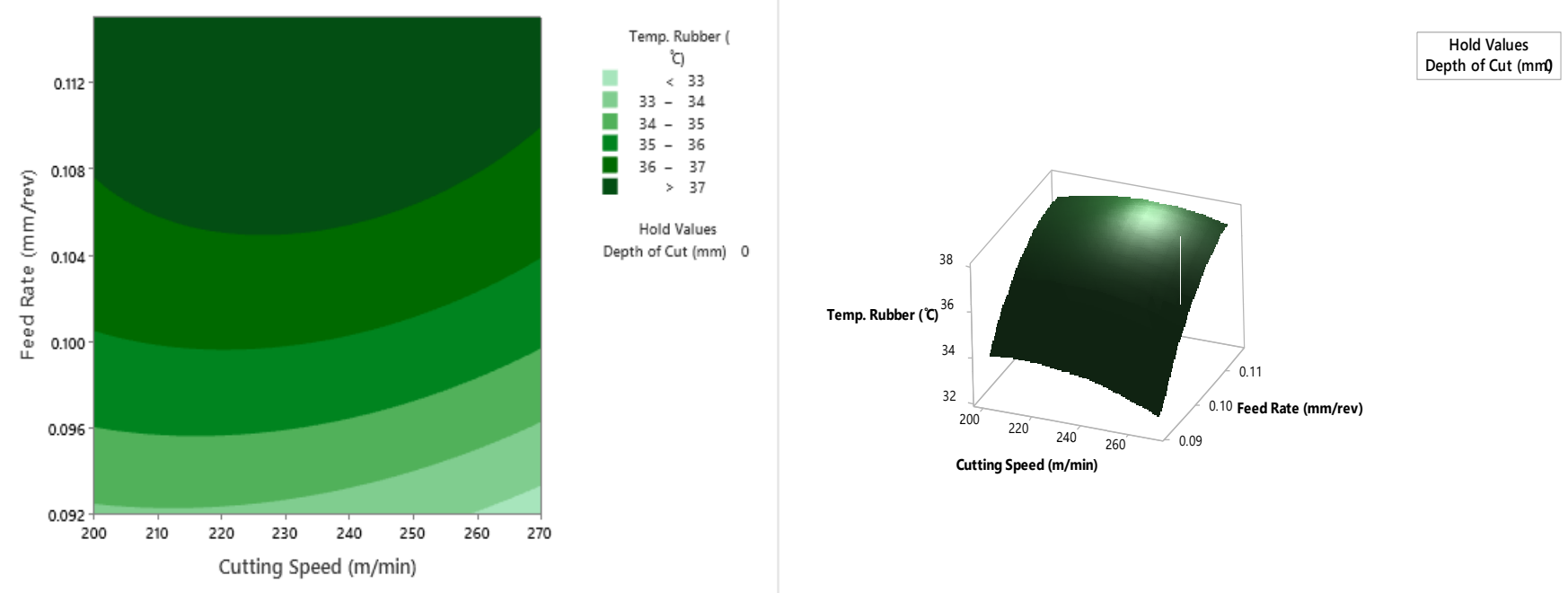

Figure 10: Contour and surface plots cutting temperature for rubber seed oil
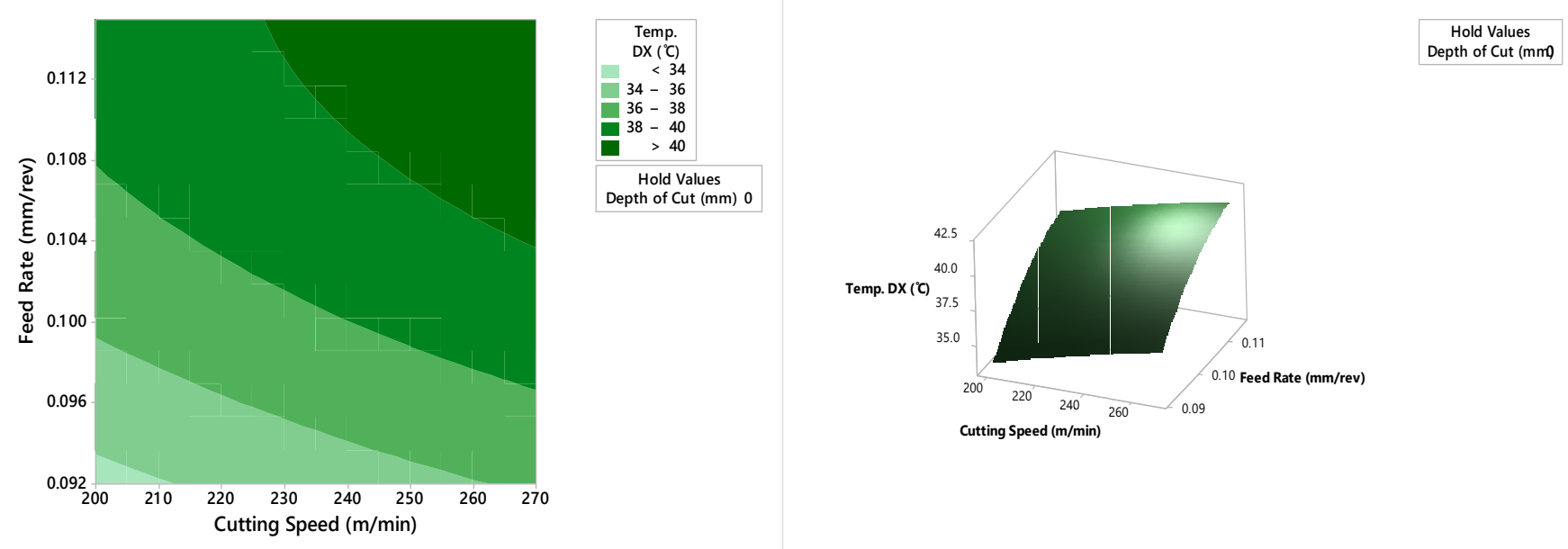

Figure 11: Contour and 3D surface plots for cutting temperature for mineral oil.

\subsection{Confirmation Test}

The model equations 1 - 4 obtained from the regression analysis in section 3.4.1 were used for the confirmation test. The experimental values, the calculated results from the model equations and the percentage error are shown in Table 9.
Percentage eror $(E)=$ $\frac{\text { Experimental }(\text { EX)value-Calculated }(C c) \text { value }}{\text { Experimental }(E X) \text { value }} \times 100$

The confirmation tests conducted using regression equations show that the results are reliable having the percentage error between $0.9 \%$ and $3.3 \%$ for the two responses.

Table 9: Confirmation test and percentage error

\begin{tabular}{llclclc}
\hline Response & \multicolumn{2}{c}{ Experimental Value } & \multicolumn{2}{c}{ Calculated Value } & \multicolumn{2}{l}{$\begin{array}{l}\text { Percentage Error (\%) } \\
\text { Rubber oil }\end{array}$} \\
& Rubber oil & Mineral oil & Rubber oil & Mineral oil & \multicolumn{2}{c}{ Mil } \\
\hline $\mathrm{Ra}(\mu \mathrm{m})$ & 0.055 & 0.061 & 0.054 & 0.059 & 1.8 & 3.3 \\
Temp. $\left({ }^{\circ} \mathrm{C}\right)$ & 35.2 & 35.4 & 34.9 & 35.9 & 0.9 & 1.4 \\
\hline
\end{tabular}

\subsection{CONCLUSION}

(i) A novel oil-in-water cutting fluid from rubber seed oil based cutting fluid has been formulated and performance evaluation was conducted as compared to the mineral oil. From the findings, the rubber seed oil based cutting fluid performed better than the mineral oil in terms of surface roughness and cutting temperature at different cutting conditions. (ii) The performance evaluation conducted indicates that the optimum conditions for surface roughness for both cutting fluids is $\mathrm{A}_{3} \mathrm{~B}_{1} \mathrm{C}_{1}$ which has a cutting speed of 270 $\mathrm{m} / \mathrm{min}$, feed rate of $0.092 \mathrm{~mm} / \mathrm{rev}$ and depth of cut of 0.7 $\mathrm{mm}$ respectively and for temperature it is obtained at $\mathrm{A}_{1} \mathrm{~B}_{1} \mathrm{C}_{1}$ which has a cutting speed of $200 \mathrm{~m} / \mathrm{min}$, feed rate of $0.092 \mathrm{~mm} / \mathrm{rev}$ and depth of cut of $0.7 \mathrm{~mm}$ respectively. 
(iii) That optimal surface roughness can be obtained at high cutting speed, low feed rate and depth of cut, while minimum cutting temperature can be obtained at low cutting speed, feed rate and depth of cut respectively.

(iv) The ANOVA results show that the feed rate has the most significant effects on the surface roughness and cutting temperature, followed by the cutting speed and depth of cut.

(v) The confirmation test conducted using regression equations show that the results are reliable having the percentage error between $0.9 \%$ and $3.3 \%$ for the two cutting fluids.

The new cutting fluid was formulated with a high concentration of water to oil ratio 9:1 with few additives that are not banned. Therefore, rubber seed oil is viable and suitable source for renewable eco - friendly cutting fluid. This study has exploited the potential of rubber seed oil for industrial purposes and it has also open up a new ground in cutting fluid sector since there is no report yet of using rubber seed oil as cutting fluid to the best knowledge of the authors. However, further study may focus on using the cutting fluid on other materials.

\section{REFERENCES}

[1] Trent,E. M. and Wright, P. K. Metal cutting, $4^{\text {th }}$ edition, Batterworth- Heineman,Boston, M.A., 2000.

[2] Abu, J. O. Manufacturing Engineering and Production Management. Aboki Publishers, 2011

[3] Zhang, S., Li, J. F., Derg, J. X. and Li, Y. S. "Investigation on diffusion wear during high speed machining Ti-6 Al-4V alloy with straight tungsten carbide tools". International Journal of Advanced Manufacturing, 44, (2009), 17 - 25

[4] Ezugwu, E. "High speed machining of aero-engine alloys". Journal of the Brazilian Society of Mechanical Sciences and Engineering, 26, (2004), $1-11$.

[5] Lawal, S. A., Choudhury, I. A. and Nukman, Y. "Evaluation of vegetable and mineral oil-inwater emulsion cutting fluids in turning AISI 4340 steel with coated carbide tools". Cleaner Production, 66, (2014), 610-618.

[6] McNutt, J. and He, Q. S. Development of biolubricants from vegetable oil via chemical modification Journal of Industrial and Engineering Chemistry, 36, (2016), 1-12.

[7] Kleinova, A.; Fodran, P.; Bmcalova, L.; Cvengros, J. "Substituted esters of stearic acid as potential lubricants". Biomass Bioenergy. 32, (2008), $366-$ 371.

[8] De Souza, M. C., Goncalves, J. F. de S., Lutif, S. Y. S., and Goma, J. de O. "Tribological evaluation of the Jatropha and tung-based oils as biolubrication A1-7050-T7451 alloy" Journal of the Brazilian Society of Mechanical Sciences and Engineering, 41(6), (2019), 243.
[9] Gui, M.M., Lee, K. I. and Bhatia, S. "Feasibility of edible oil vs. non-edible oil vs. waste edible oil as biodiesel feedstock". Energy, 33, (2008), 1646 1653.

[10] Sahana, V. N., and Kumar, R. C. "Manufacturing of pongamia oil based bio-lubricant for machining application". International Research Journal for Engineering and Technology, 6, (2019), 16391645.

[11] Woma, T. Y., Lawal, S. A., Abdulrahman, A. S, MA, O., and MM, O. "Vegetable oil based lubricants challenges and prospects". Tribology Online. 14(2), (2019), 60-70.

[12] Uzu, F. O., Ihenyen, G. A., Chukwuma, F. and Imoebe, S. O. Processing, analysis and utilization of rubber seed oil and cake. paper presented at the National Conference on Industrial utilization of natural rubber seed, latex and wood. Rubber Research Institute of Nigria, Benin City. 7, 1985.

[13] Aigbodion, A. I. "Effect of storage of seeds on quality of rubber seed oil". India Journal of Natural Rubber, 92, (1994), 141 - 143.

[14] Abdalla, B. M. and Salimon, J. "Physicochemecal characteristics of Malysian rubber (Heaea Brasiliensis) seed oil". European Journal of Scientific Research., 3, (2009), 437 - 445.

[15] Aigbodion, A. I. and Pillai, C. K. S. "Preparation, analysis and applications of rubber seed oil and its derivatives in surface coating". Progress in Organic Coating, 38, (2000), 187192.

[16] Njoku, O. U., and Ononogbu, I. C. "Preliminary studies on preparation of lubricating greases from bleached rubber seed oil'. Ind J N R Res. 8, (1995), 140-141.

[17] Okie-Aghughu, O. Aluyor, E.O. and Adewole, E.S. "Use of rubber seed oil as baes fluid in the formulation of oil-based drilling mud". Advanced Materials Research, 824, (2013), 401- 405.

[18] Aravind, A., Joy, M.K. and Nair, K.P. "Lubricants properties of biodegradable rubber tree seed (Hevea-brasiiensis Muell. Arg) oil". Industrial Crops and products, 74, (2017), 14- 19.

[19] Kawato, Y., Kamiusuki, T. and Watanabe, S. 'Water-soluble metalworking fluid additives derivatives of 3 mercaptopropionic acid", Journal of Surfactants and Detergents. (2006), $391-400$.

[20] Akpan, U. G., Jimoh, A. S. and Mohammend, A. D. "Extraction, characterization and modification of castor seed oil". Leonardo Journal of Sciences, 8, (2006), $43-52$.

[21] Nagaraj, G. and Mukta, N. "Seed composition and fatty acid profile of some tree borne oilseeds". Journal Oilseeds Research, 21, (2004), 117 - 120.

[22] Chauhan, P.S. and Chhibber, V. K. "Non-edible oil as a source of bio-lubricant for industrial applications: A review". International Journal of Engineering and Innovative Technology, 2, (2013), $299-305$. 
[23] Agu, C. K.., Lawal, S. A., Abolarin, M. S., Agboola, J. B., Abutu, J. and Awode, E. I. "Multi- response optimisation of machining parameters, in turning AISI304L using different oil based cutting fluids". Nigerian Journal of Technology), 38, (2019), $364-375$.

[24] Da Silva, N. D., Batistella, B. C., Filho, M. R. and Maciel, W. R. "Optimization of biodiesel production from castor oil". Applied Biochemistry and Biotechnology, 13, (2006), $405-414$.

[25] Raja, S. A., Smarth, D. S. R. and Lee, R. L. C. "Biodiesel production from jatropha oil and its characterization". Research Journal of Chemical Sciences, 1, (2001), 81-87.
[26] Shah, M. and Potdar, V.V. "Study of the effect of vegetable oil based cutting fluid on machining characteristics of AISI 316L steel". Recent Trends In Mechanical Engineering, (2015), 1-6.

[27] Jeevan, T.P. and Jayaram, S. R. "Performance evaluation of jatropha and pangamia oil based environmentally friendly for turningAA6061", Hindawi, Advanced in Tribology, (2018), 1- 9.

[28] Talib, N. and Rahim, E.A. "Performance evaluation of chemically modified crude jatropha oil as a biobased metalworking fluid for machining process". Proceedings CIRP $12^{\text {th }}$ Global conference on Sustainable Manufacturing, 26, (2015), 346 - 350. 